\title{
Microbiology Susceptibility Agent Name
}

National Cancer Institute

\section{Source}

National Cancer Institute. Microbiology Susceptibility Agent Name. NCI Thesaurus. Code C162147.

The name of the agent for which resistance is tested. The agent specified may be based on genetic markers or direct phenotypic drug sensitivity testing. 